\title{
Experimental Study on the Ultrasonic Testing including Porosity of Rock Damage Characteristics
}

\author{
Jinhao Zhang, Hongkai Chen, He Wang \\ Institute of Geotechnical Engineering, Chongqing Jiaotong University, Chongqing, China \\ Email:yunandhao@163.com
}

How to cite this paper: Zhang, J.H., Chen, H.K. and Wang, H. (2017) Experimental Study on the Ultrasonic Testing including Porosity of Rock Damage Characteristics. Journal of Geoscience and Environment Protection, 5, 19-29.

https://doi.org/10.4236/gep.2017.52002

Received: October 12, 2016

Accepted: February 7, 2017

Published: February 14, 2017

\begin{abstract}
Cement mortar specimens are used to simulate the fracture of rock material under uniaxial compression test, using the ultrasonic instrument measurement test process, the waveform and wave velocity results along with the change of specimen fracture extension are obtained. Experimental results show that at $0 \mathrm{MPa}$, there are micro-defects in the specimen, leading to the irregular change of the waveform of the measuring points $4 \#$ and 5\#; At $1-4$ $\mathrm{MPa}$, there is no crack on the surface of the specimen, the waveform of ultrasonic wave is stable, and the velocity of each point increases with the increase of the strain, but the measuring point increases the wave velocity when the load is applied; When the specimen surface cracks, expect the waveform of measuring point $4 \#$ and $5 \#$ change in irregularities, the measuring point $2 \#$ waveform also changes irregularly and measuring point of the wave velocity has decreased; At the crack propagation stage, ultrasonic wave also changes irregularly along with the expansion of crack, wave velocity with the increase of the strain is also obvious downward trend; When the crack penetrates the whole specimen, the waveform of each measuring point changes abnormally, the continuity is bad, the waveform is irregular and the measured wave velocity is low.
\end{abstract}

\section{Keywords}

Rock Mechanics, Uniaxial Compression Test, Ultrasonic Testing, Waveform and Wave Velocity, Fracture Rock

\section{Introduction}

With the construction of the Three Gorges Project of the Yangtze River and the rapid development of the West Region, a large number of rock mechanics and 
geotechnical engineering problems appear. Most of these projects are built in the central and western mountainous areas of our country, which involve many complex rock mechanics problems. For example, engineering design, construction, stability evaluation and rock mass reinforcement are directly depend on the strength, deformation, structural plane and failure law of rock mass. A large number of engineering practice shows that almost all of the unstable rock mass failure is not appearing at the beginning. Due to the existence of initial crack or defect, the stress concentration is very easy to occur at the crack tip, which leads to the re distribution of stress field and displacement field. Under certain external factors (load, temperature and groundwater, etc.), it caused crack initiation and extension, the corresponding changes will cause structural properties of materials. With the continuous expansion of the microstructure defects, the macroscopic mechanical properties of the rock materials are deteriorated, resulting in macroscopic fracture or failure. Therefore, it is very important to study the damage characteristics of fractured rocks and to analyze the variation of fracture for explaining its destruction mechanism.

In recent years, ultrasonic as an important non-destructive testing technology has the advantages of strong penetrability, simple equipment, good condition and safety, wide detection range and so on. It has been used as an important means to study the damage and fracture mechanism of rock materials. Brich [1] found that the longitudinal wave velocity of the rock was linearly positive with the density of the rock; Simmons [2] analyzed the $\mathrm{CaO}$ content on the impact of changes in velocity based on this theory and obtained empirical formula; Walsh et al. [3], studies have shown that in the compaction process, the ultrasonic wave velocity in the rock increases with the load increasing and decreases with the load increasing in the expansion stage; Willis's [4] studies have shown that when ultrasound wave propagation in fractures, will produce reflection, refraction, scattering and other phenomena, and the form of propagation is accord to the ultrasonic wave length and crack linear size; Freund [5] studied the vertical and transverse velocities of sedimentary clastic rocks with porosity, clay content and confining pressure; Khaksar [6] found that the compressional and shear wave velocities of dry gas-bearing sand layers are approximated by the power function. Pei Zhenglin et al. [7], presented the the change rule and the fracture properties of relations among the first wave, the coupling wave and the coda waves, through the comprehensive study of the full wave waveform of the ultrasonic penetration signal of the ideal fracture system in the rock; Chen Gengye et al. [8], derived the relationship between damage parameters and attenuation coefficient and use energy method for basalt damage and stress attenuation test experimental study based on the analysis of rock fissure damage sound attenuation; Zhao Mingjie [9] proposed the equivalent model by using the relationship between rock deformation characteristics, void ratio, equivalent elastic parameters and wave velocity and attenuation, and established the theoretical relationship between sound velocity and attenuation and stress during loading and unloading; Shi Jinjin et al. [10], use rock specimens for impact damage experiments, 
and obtained impact damage characteristics and damage degree of the rock and the rate of the change of sound wave velocity; Han Fang et al. [11], evaluated the degree of damage to the rock block through the ultrasonic testing to quantitatively; Li Xianglong et al. [12], studied the relationship between damage of rock material and wave length and amplitude of stress wave by using the law of stress wave parameters on the damage and failure of rock material; Liang Tiancheng et al. [13], measured the acoustic emission and ultrasonic wave velocity of rock during uniaxial compression damage, and compared the changes of acoustic emission and wave velocity with the damage process; Yuan Xiaoping et al. [14], established meso-mechanical model of rock microcrack propagation, studied the meso-damage and plasticity of rock, and analyzed the damage and macroscopic plasticity of the model from confining pressure and short micro-crack length.

At present, the research on fracture characteristics and crack propagation law of fractured rock has been relatively mature, but little is done on the experiment and mechanism of damage characteristics of fractured rock. In this paper, cement mortar specimens are used to simulate the fracture of rock materials with uniaxial compression test, and during the process of ultrasonic instruments measuring the test, waveform and velocity with the specimen crack growth results are obtained. The analysis of damage mechanism of cracked specimens provides a powerful basis for studying the extension mechanism of rock materials from microscopic damage to macroscopic fracture, which provides scientific basis for engineering application.

\section{Preparation of Test Equipment and Test Specimens}

The RMT-301 multi-function electro-hydraulic servo testing machine developed by Wuhan Institute of Rock and Soil Mechanics, Chinese Academy of Sciences was used to test the uniaxial compression of fractured rock. Displacement control is used to observe the change of fracture during compression. The waveform and wave velocity in the process of uniaxial test were measured by DJUS- 05 nonmetallic ultrasonic instrument. The waveform and velocity were recorded with the crack propagation of the specimen to meet the needs of the experiment and basic theoretical research.

Specimen ordinary portland cement, strength class $42.5 \mathrm{MPa}$; cement, river sand, water mixing ratio is 1:3:0.72; the length, width and height are $150 \mathrm{~mm}$, $150 \mathrm{~mm}$ and $150 \mathrm{~mm}$ respectively. Pre-fracture production of iron sheet is designed according to the angle and length of the ramp into vibrator good cement mortar test block, the iron sheet from the edge of the specimen $30 \mathrm{~mm}$, and wait for a fixed sheet test block condensation, after the trial molding (48 hours) removed and conservation to a predetermined age (28 days) the experiment (Figure 1). The symmetrical surface of the specimen is chosen as the grid line to facilitate the alignment of the ultrasonic test points. Six ultrasonic test points are arranged on the symmetry plane. L1\# - L6\# are the launching points, R1\# - R6\# are the receiving points, shown Figure 1 and Figure 2. 


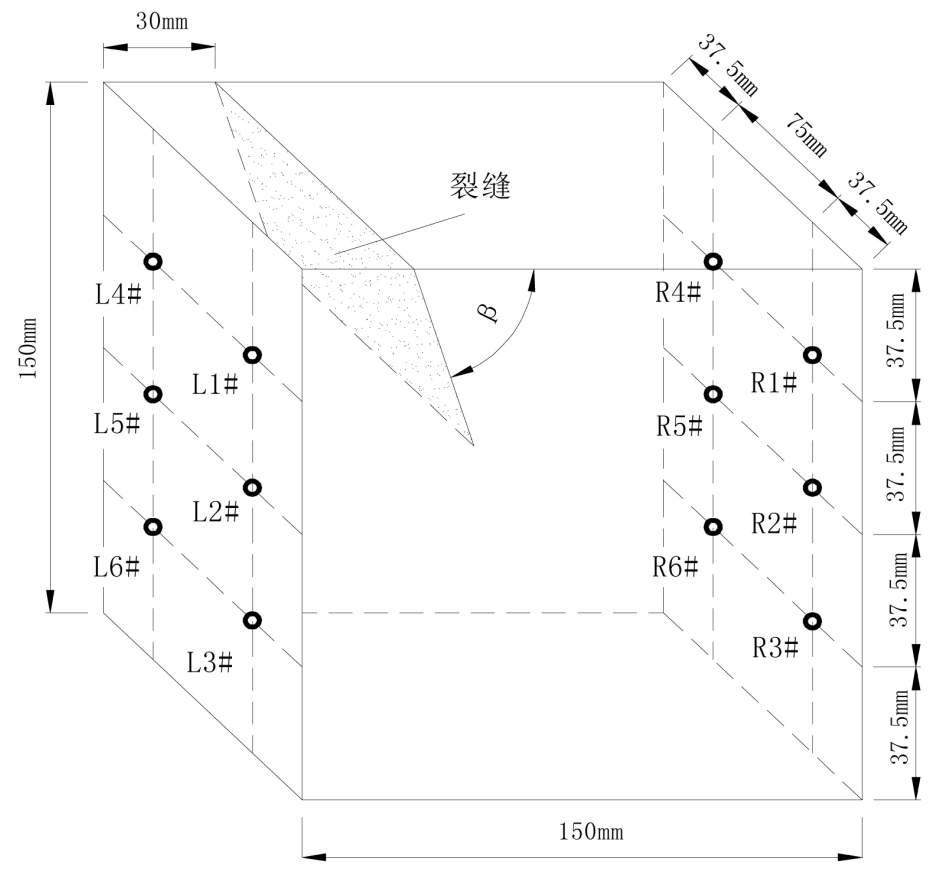

Figure 1. Three dimensional map of ultrasonic measurement points (The black (O): show measuring point).

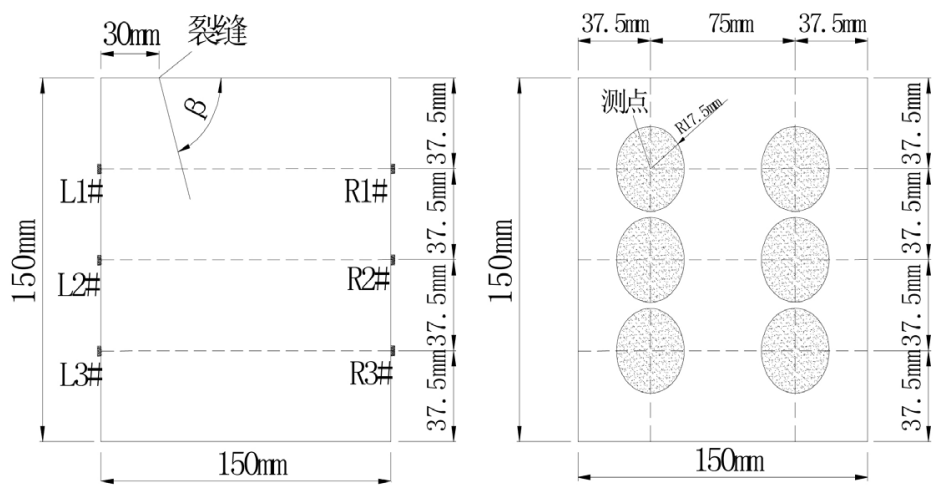

Figure 2. Ultrasonic measurement point layout plan.

\section{The Test Results and Analysis}

In the test machine for uniaxial compression, the displacement control, the medium displacement rate of $0.002 \mathrm{~mm} / \mathrm{s}$, each level of load increase of $1 \mathrm{MPa}$ in the progressive application of load. When loaded into the load at each level, keep the load 1 - 2 minutes, manually control the send and receive ultrasound transducer, ultrasonic waveform acquisition for each test point. As all the specimens are in the same proportion, conservation period, the production made its internal composition of matter is the same. In the uniaxial compression load, ultrasonic propagation in each specimen is the same, that is, when the ultrasonic transmission to the defect area, the wave penetrating ability is greatly weakened, resulting in abnormal waveform changes, poor continuity, waveform irregular, ultrasonic wave propagation velocity will be reduced. The test results of cracked specimens are listed here, and the changes of the ultrasonic waveforms in each 
stage (0 MPa, $1 \mathrm{MPa} \ldots$, cracks to the specimen surface, and crack propagation to specimen failure) are analyzed. Their experiments and compressive failure mechanism are explained, as shown in Figure 3.

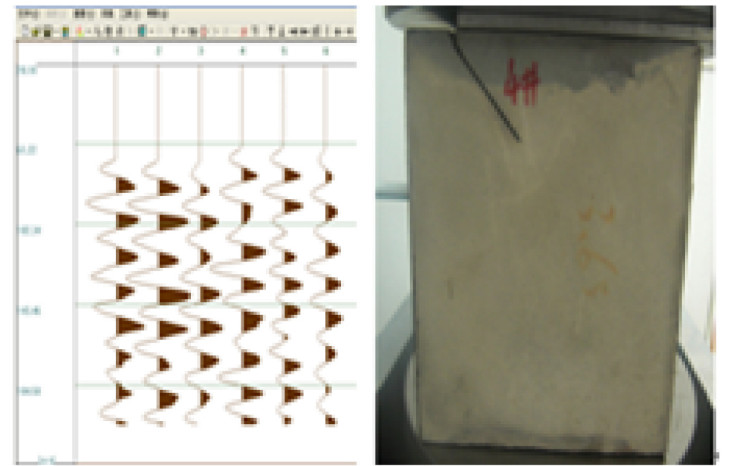

(a) $0 \mathrm{MPa}$

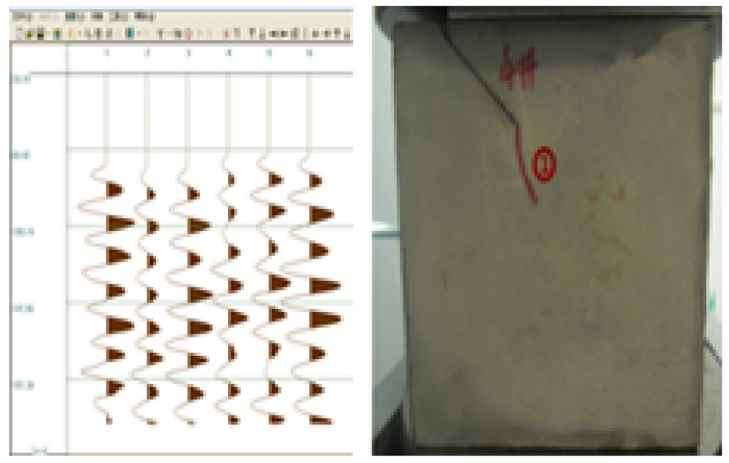

(c) surface cracks

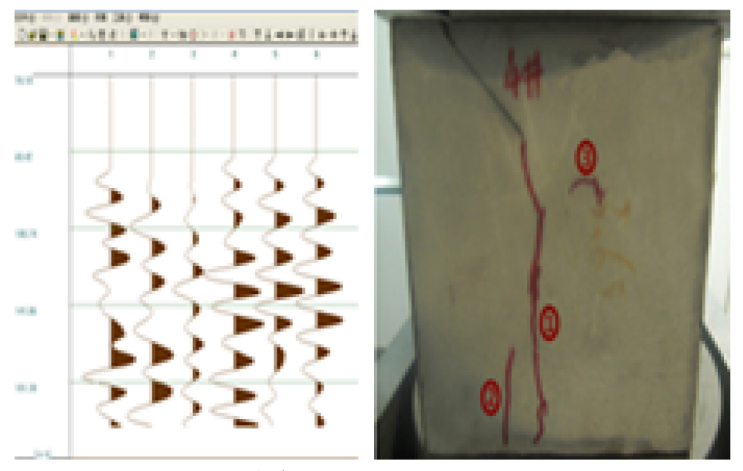

(e) Crack extension 2

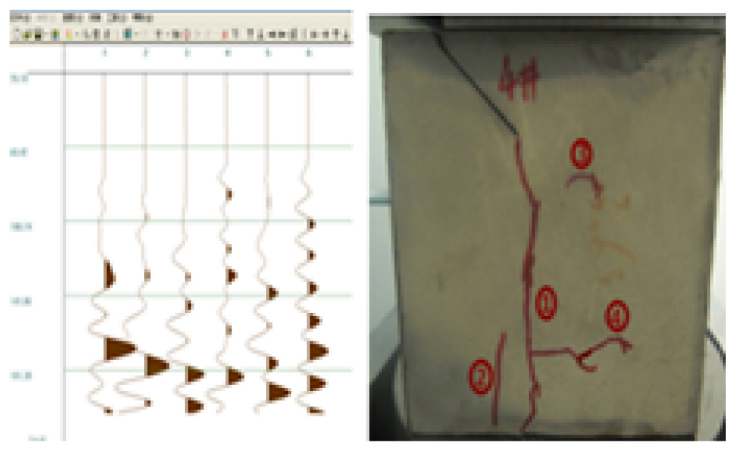

(g) Specimen damage

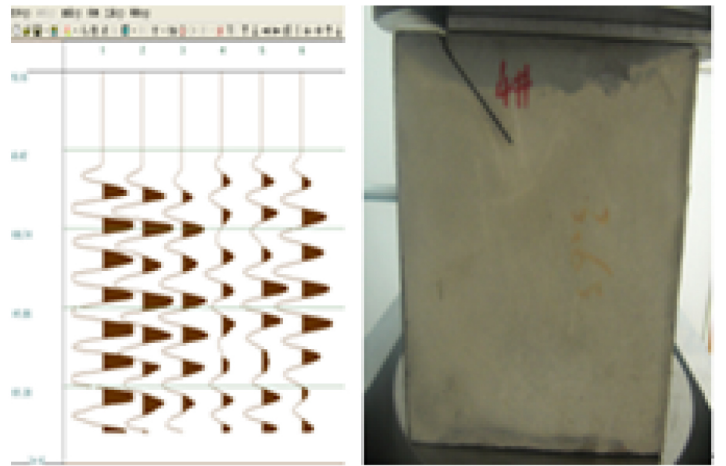

(b) 1-4 MPa

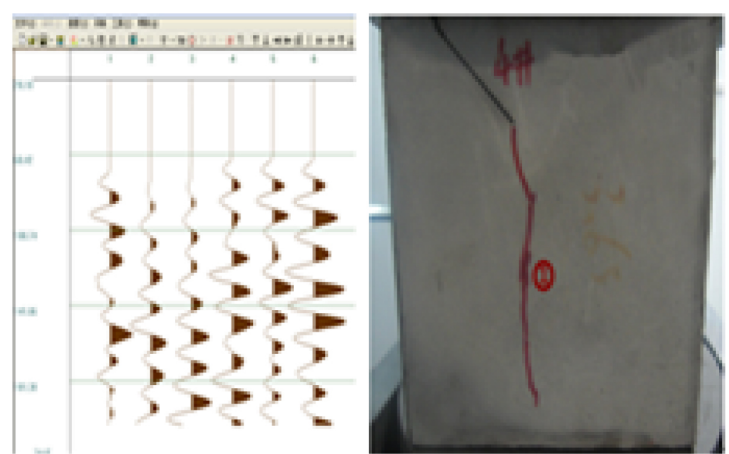

(d) Crack extension 1

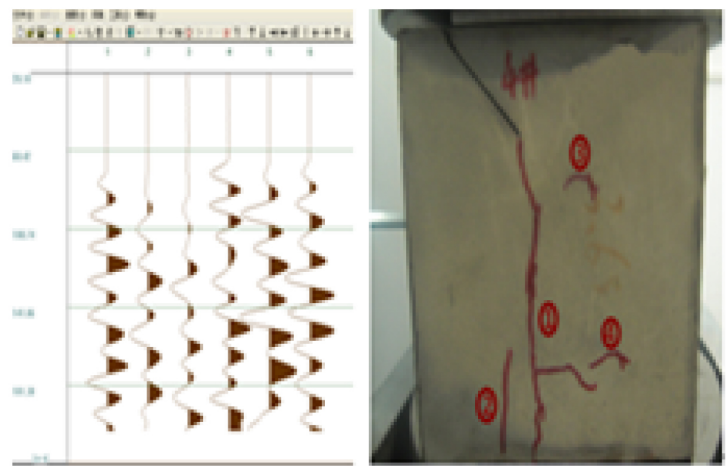

(f) Crack extension 3

Figure 3. Ultrasonic wave of specimens (Note: the waveform of the measuring point 1 - 6 represents the measuring point $1 \#-6 \#$, the wave propagation distance of $150 \mathrm{~mm}$.). 


\subsection{The Changing Rule of the Ultrasonic Wave in the Process of Specimen under Pressure}

The experimental results show that there are micro-defects in the specimen at 0 $\mathrm{MPa}$, which lead to the irregular change of the waveform of the test point 4 and the test point 5 . In particular point $5 \#$, the whole waveform and other test points are quite different, the continuity of peaks and valleys is also poor, indicating a small area around the test point $5 \#$, the micro-defects of the specimen is relatively concentrated (Figure 3(a)). In the range of 1 to $4 \mathrm{MPa}$, no crack appeared on the surface of the specimen, and the tip of individual microcracks in the specimen was concentrated due to stress and developed in a small range, there are also most of the micro-cracks and holes due to the role of compressive stress closed, the waveform of the ultrasonic wave tends to be stable, Changes in waveform is not obvious, irregular test points are still test points 4\# and 5\#, other test point waveform line is regular and continuous (Figure 3(b)). Continue to load, when the specimen surface cracks, in addition to the test points $4 \#$ and $5 \#$ irregular waveform changes outside the test point $2 \#$ waveform also irregular changes. It is shown that the microcracks are connected with the new microcracks in the small area of the test point 2\#. As the load increases, the microcracks continue to be connected and the internal crack spreads to the specimen surface (Figure 3(c)). During the crack stage, initial cracks continued to spread rapidly, the test piece deformation continues to increase, micro-cracks also continued to extend, connect, development to the specimen surface, it would appear more fractured specimen surface. The waveform of ultrasonic wave will also change irregularly with the expansion of crack, the most obvious change is the test points $1 \#, 2 \#, 3 \#$, these three test points waveforms are no longer continuous, The difference between the peak and trough of large (Figures 3(d)-(f)). When the crack penetrates through the specimen, the specimen has lost its load-carrying capacity, and the instability fracture occurs. The crack penetrating is roughly parallel to the compressive stress direction, and the specimen is divided into several small parts. At this time the waveform of each measurement point abnormalities vary greatly, continuity is poor, the waveform is obviously irregular (Figure $3(\mathrm{~g})$ ).

\subsection{The Changing Rule of the Ultrasonic Wave Velocity in the Process of Specimen under Pressure}

Crack specimen under uniaxial compression, with the gradual application of stress, its internal micro-cracks will continue to develop until the final complete destruction. The results show that [15], ultrasonic longitudinal wave velocity is more sensitive to stress. Ultrasonic P-wave velocity can reflect the relationship between internal damage and macroscopic fracture under uniaxial compression. In this paper, crack specimen strain in the process of change by force, and establish the relationship between strain velocity of change, ashen come to damage deformation characteristics during load test piece (Table 1, Figure 4).

It can be seen from Table 1 that under the uniaxial compression of the cracked 
Table 1. Contains the fractured specimen ultrasonic wave velocity test results.

\begin{tabular}{|c|c|c|c|c|c|c|c|}
\hline & & $\begin{array}{l}\text { measure } \\
\text { point } 1 \#\end{array}$ & $\begin{array}{l}\text { measure } \\
\text { point } 2 \#\end{array}$ & $\begin{array}{l}\text { measure } \\
\text { point 3\# }\end{array}$ & $\begin{array}{l}\text { measure } \\
\text { point } 4 \#\end{array}$ & $\begin{array}{l}\text { measure } \\
\text { point } 5 \#\end{array}$ & $\begin{array}{l}\text { measure } \\
\text { point 6\# }\end{array}$ \\
\hline Stress/MPa & $\left(\times 10^{-3}\right)$ & $\begin{array}{c}\text { Wave } \\
\text { velocity } \\
/ \mathrm{km} / \mathrm{s}\end{array}$ & $\begin{array}{c}\text { Wave } \\
\text { velocity } \\
/ \mathrm{km} / \mathrm{s}\end{array}$ & $\begin{array}{c}\text { Wave } \\
\text { velocity } \\
/ \mathrm{km} / \mathrm{s}\end{array}$ & $\begin{array}{c}\text { Wave } \\
\text { velocity } \\
/ \mathrm{km} / \mathrm{s}\end{array}$ & $\begin{array}{c}\text { Wave } \\
\text { velocity } \\
/ \mathrm{km} / \mathrm{s}\end{array}$ & $\begin{array}{c}\text { Wave } \\
\text { velocity } \\
/ \mathrm{km} / \mathrm{s}\end{array}$ \\
\hline 0 & 0 & 3.04 & 3.03 & 3.06 & 3.36 & 3.36 & 3.41 \\
\hline 0.99 & 0.93 & 3.08 & 3.05 & 3.07 & 3.39 & 3.40 & 3.42 \\
\hline 1.98 & 1.58 & 3.11 & 3.05 & 3.07 & 3.41 & 3.40 & 3.43 \\
\hline 2.82 & 2.19 & 3.12 & 3.06 & 3.09 & 3.42 & 3.39 & 3.42 \\
\hline 3.69 & 2.95 & 3.09 & 3.05 & 3.09 & 3.39 & 3.40 & 3.43 \\
\hline $\begin{array}{l}\text { Specimen surface } \\
\text { cracks }(4.69)\end{array}$ & 3.64 & 3.01 & 2.95 & 2.99 & 3.36 & 3.37 & 3.39 \\
\hline $\begin{array}{c}\text { Crack extension } \\
\text { stage } 1 \\
(5.42)\end{array}$ & 4.53 & 2.97 & 2.74 & 2.85 & 3.21 & 3.10 & 3.20 \\
\hline $\begin{array}{c}\text { Crack extension } \\
\text { stage } 2 \\
(7.48)\end{array}$ & 5.28 & 2.89 & 2.69 & 2.78 & 3.23 & 3.04 & 3.16 \\
\hline $\begin{array}{c}\text { Crack extension } \\
\text { stage } 3 \\
(9.48)\end{array}$ & 6.17 & 2.87 & 2.56 & 2.68 & 3.13 & 3.04 & 3.14 \\
\hline Specimen damage & 8.06 & 2.58 & 2.59 & 2.61 & 2.59 & 2.67 & 2.97 \\
\hline
\end{tabular}

specimen, the velocity of each point increases with the increase of the strain in the range of small initial load, the velocity of the wave is increased when the load is applied. This is because the fractured specimen is compressed to cause some micro-cracks to be compacted, the wave propagation within the specimen to reduce the resistance, making the wave speed has increased, but the increase is very small. When the specimen surface cracks, each test point velocities have decreased, but the test points $1 \#, 2 \#, 3 \#$ wave speed decreased significantly, test point $4 \#, 5 \#, 6 \#$ of velocity fluctuations unlikely. This is because the sample in the production process, the $1 \#, 2 \#, 3 \#$ points belong to the upper part of the test, the specimen, due to settlement of mortar particles leads to the specimen, density distribution is not uniform, and upper part of the internal space is more than half, making waves in the specimen spread by the gap resistance increases, the wave velocity decreased significantly. With the increase of load, the internal micro-cracks will continue to develop, until the final complete destruction, the velocity of each test point also increases with the strain was a significant downward trend.

It can be seen from Figure 4 that the measurement points have similar velocity-strain characteristics. The general rules are as follows:

1) The initial velocity values of $3 \#, 2 \#$ and $1 \#$ are relatively close, and the wave velocity-strain characteristic curves of $3 \#$ and $2 \#$ are similar;

2) The initial velocity values of $4 \#, 5 \#$ and $6 \#$ are relatively close, and the wave 




Figure 4. Contains fracture specimen compression wave velocity-strain diagram.

velocity-strain characteristic curves of $5 \#$ and $6 \#$ are similar;

3) The wave velocity-strain curves of test points $1 \#$ and $4 \#$ show anomalous characteristics, because there are arranged on both sides of the original crack, and the original cracks will produce a closed phenomenon; The original micro-cracks within the specimen will expand, new cracks will appear and develop an extension. It is difficult to explain the rise and fall of the wave velocity due to the situation that the wave velocity of ultrasonic wave will rise and then decline (crack growth stage) in the whole process of stress of the specimen, unable to determine changes in the relationship between damage and fracture of the specimen. Therefore, the wave velocity-strain curves of test points $1 \#$ and $4 \#$ can not describe the deformation law of the test.

4) The characteristic of the whole wave velocity strain curve is

a) The prefabricated cracks and the microcracks inside the specimen are in steady state when the load is small. Section perpendicular to the loading direction of the micro-cracks will have closed, the specimen is compacted and wave velocity increases slightly; Parallel to the loading direction of the micro-crack-tip stress concentration slightly development, resulting in a downward trend but the velocity was not obvious; The whole wave velocity-strain curve is stable and the wave velocity is almost unchanged or slightly increasing or decreasing.

b) When the specimen surface cracks decreased velocity. The original microcracks developed and extended within the specimen, and new microcracks gradually expanded with the increase of the load; the microcracks developed more frequently in the specimens, which led to the development of micro cracks and the macroscopic cracks appear on the surface. It can also be seen from the velocity-strain curve of each test point that the wave velocities of the test points 2\# and 3\# show the obvious drop firstly at the surface of the specimen, while the test points $5 \#$ and $6 \#$ in the surface of the specimen cracks after a period of time, it showed a marked decrease in velocity. It is shown that the macroscopic cracks on the specimen surface are only partial cracks and do not penetrate the whole 
specimen. If the loading is stopped, the expansion of the local crack will cease. If the load continues to be applied, the stress will continue to increase with the strain, local cracks and prefabricated cracks will continue to extend the extension.

c) As the load continues to be applied into the crack propagation stage. With the increase of the strain, the ultrasonic wave velocity decreases sharply, the inner micro crack propagation and the extension of the specimen are not stable, there are several macroscopic cracks on the surface of the specimen, and the length of the crack is different and distribution of random.

d) Cracks continue to develop rapidly, leading to serious damage to the test pieces and can not withstand the load. Although many small pieces of the specimen will be gradually compacted, will make some of the measured point of the wave speed has increased, but the whole wave velocity-strain curve is in a downward trend. When the fracture completely penetrated the specimen internal and surface, the specimen was damaged continuously, and the phenomenon of unstable fracture occurs.

\subsection{Mechanism of Ultrasonic Detecting Damage Characteristics of Fractured Specimen}

In summary, the mechanism of ultrasonic testing on the damage characteristics of cracked specimens is that there are initial micro defects and prefabricated cracks, which lead to irregular changes in the shape of the waveform. Under the action of uniaxial compression, the whole specimen has undergone five stages: compaction, elastic deformation, damage, damage extension and damage. In the compaction stage, the tip of the individual microcracks in the specimen is developed with a small concentration due to the stress concentration, and most of the microcracks and holes are closed by the compressive stress, ultrasonic propagation time will be shortened due to the compression of the specimen and wave speed will increase. In the stage of elastic deformation, which aggregates the stress test compression effect showed the most elastic deformation, internal micro cracks would not extend, even if there are individual micro-cracks develop slightly but the residual deformation is small and ultrasonic wave velocity will tends to a stable value. At the stage of damage, there is no obvious macroscopic crack on the surface of the specimen, and does not appear to fall off. The wave velocity of the ultrasonic wave will be decreased, but not obvious. The threephase waveforms do not change significantly due to the absence of significant cracks in the specimen surface. Continue to load, the waveform appears due to the occurrence of irregular irregularities when the specimen surface cracks, wave velocity is also suddenly reduced. In the crack propagation phase, the waveform of ultrasonic wave will also change irregularly and wave velocity of ultrasonic wave will decrease with the expansion of the crack. When the crack penetrates through the whole specimen, the specimen has lost its bearing capacity, and the instability of the specimen occurs. At this time the waveform abnormalities vary greatly, continuity is poor, the waveform was irregular, measured wave velocity 
was significantly lower. It can be seen that the nature of damage and failure of fracture specimen is the process of transforming the continuous material into a discontinuous damage body by continuous accumulation step by step.

\section{Conclusions}

Firstly, Using the uniaxial compression tests and ultrasonic instrument measurement, the specimens of each stage in the process of loading waveform and wave velocity were obtained.

Secondly, Through the various stages of oscillogram it can be concluded: at 0 $\mathrm{MPa}$, specimen within micro defects, lead to point $4 \#$ and $5 \#$ of the measured points and waveform appears irregular change; At 1 - $4 \mathrm{MPa}$, specimen surface without cracks, ultrasonic wave tends to be stable, the change of waveform figure is not very big, irregular change point are still the point of $4 \#$ and measuring point 5\#, other measuring points' waveforms are still regular and continuous; When the specimen surface cracks, expect the waveform of measuring point $4 \#$ and 5\# change in irregularities, the measuring point $2 \#$ waveform also changes irregularly; In point $2 \#$ of a small scale, micro cracks specimens within the original and new micro cracks have been connected, internal crack extension to the surface of specimen. In the crack propagation stage, ultrasonic wave may also be along with the expansion of crack and irregular change, the most obvious change is point $1 \#, 2 \#, 3 \#$ three points waveform is no longer continuous, difference is very big between peaks and troughs; When the crack penetrates the whole specimen, the waveform of each measuring point changes abnormally, the continuity is bad, the waveform is irregular .

Thirdly, Through the measurement of each measuring point velocity, it found that in the early stage of the load of smaller scope, each point in the wave velocity with the increase of the strain and strain ratio is not obvious, the wave velocity of measuring point is increased when the load is applied. When cracks on the surface of the specimens, all measuring points' velocity decreased, but the station 1\#, 2\#, 3\# wave velocity decreased significantly, measuring point 4\#, 5\#, 6\# wave velocity fluctuation is not obvious. With the increase of load, each measuring point velocity with the increase of the strain is also obvious downtrend.

Fourthly, By strain and velocity, wave velocity and the strain relationship curve is drawn. Curve shows that the initial velocity values of the measuring points 1\#, 2\# and 3\# are close to each other and point 2\# and 3\# wave-strain curves in similar characteristics; the initial velocity values of the measuring points $4 \#, 5 \#$ and 6\# are close to each other and point 5\# and 6\# wave-strain curves in similar characteristics.

\section{Acknowledgements}

This study in the paper was funded by The National Natural Science Foundation of China (No. 11272185, 51678097 and 50678182), and Chongqing University Innovation Team; The study Financially supported by the Program (201309) for Par-Eu Scholars in Chongjing. 


\section{References}

[1] Birch, F. (1960) The Velocity of Compressional Waves in Rocks to 10 Kilobars, Part 1. J Geophys Research, 65, 1083-1102. https://doi.org/10.1029/JZ065i004p01083

[2] Simmons, G. (1964) Velocity of Shear Waves in Rocks to 10 Kilobars. J Geophys Research, 69, 1123-1130. https://doi.org/10.1029/JZ069i006p01123

[3] Walsh, J.B., Brace, W.F. and England, A.W. (1965) The Effect of Porosity on Compressibility of Glass. Am Ceram Soc, 48, 605-608. https://doi.org/10.1111/j.1151-2916.1965.tb14687.x

[4] Willis, J.R. (1980) A Polarization Approach to the Scattering of Elastic Waves-I: Scattering by a Singleinclusion. J Mech Phys Solids, 28, 287-305. https://doi.org/10.1016/0022-5096(80)90021-6

[5] Freund, D. (1992) Ultrasonic Compressional and Shear Velocities in Dry Clastic Rocks as a Function of Porosity, Clay Content, and Confining Pressure. Geophysical Journal International, 108, 125-135. https://doi.org/10.1111/j.1365-246X.1992.tb00843.x

[6] Khaksar, A., Griffiths, C.M. and Mccann, C. (1999) Compressional- and ShearWave Velocities as a Function of Confining Stress in Dry Sandstones. Geophysical Prospecting, 47, 487-508. https://doi.org/10.1046/j.1365-2478.1999.00146.x

[7] Pei, Z.L. (1990) Preliminary Study on Ultrasonic Propagation Law of Rock Fracture Model. Editorial Office of Site Investigation Science and Technology, 5, 60-63.

[8] Chen, G.Y., Li, Z.D. and Liu, B. (1995) Experimental Study on the Effect of the Crack Damage on Ultrasonic Wave Attenuation in Rocks. Gold, 16, 15-20.

[9] Zhao, M.J. (1999) A Study on Ultrasonic Properties of Cracked Rockmass under Loading and Unloading. Chongqing Jianzhu University, Chongqing.

[10] Shi, J.J., Guo, X.B., Xiao, Z.X., et al. (2005) Experimental Study on Ultrasonic Velocity and Damage Properties of Rock under Dynamic Loading. Mining Research and Development, 25, 27-29.

[11] Han, F., Ji, H.G. and Zhang, W. (2007) Relationship between the Acoustic Characteristics and Damage Variable in the Process of Uniaxial Loading and Unloading. Journal of University of Science and Technology Beijing, 29, 452-455.

[12] Li, X.L., Liu, D.S., Dong, X., et al. (2009) Study on Relationship between Rock Material Damage and Stress Wave Parameters. Blasting, 26, 6-9.

[13] Liang, T.C., Ge, H.K., Guo, Z.W., et al. (2012) Evaluation of Rock Damage State with Acoustic Emission and Velocity Variation. Earthquake Research in China, 28, 154-166.

[14] Yuan, X.P., Liu, H.Y. and Wang, Z.Q. (2013) Crack-Mechanics Damage and Plasticity for Rock-Like Materials under Compressive Loading. Chinese Journal of Computational Mechanics, 30, 149-154.

[15] Jason, J. and Hult, J. (1977) Fracture Mechanics and Damage Mechanics. A Combined Approach. J. de Mech Appl, 1, 59-64. 
Submit or recommend next manuscript to SCIRP and we will provide best service for you:

Accepting pre-submission inquiries through Email, Facebook, LinkedIn, Twitter, etc. A wide selection of journals (inclusive of 9 subjects, more than 200 journals)

Providing 24-hour high-quality service

User-friendly online submission system

Fair and swift peer-review system

Efficient typesetting and proofreading procedure

Display of the result of downloads and visits, as well as the number of cited articles Maximum dissemination of your research work

Submit your manuscript at: http://papersubmission.scirp.org/

Or contact gep@scirp.org 